\title{
Influence of the phase inversion on mould-shrinkage, mechanical- and burning properties of polymer blend
}

\author{
Károly Dobrovszky ${ }^{1, a}$, Ferenc Ronkay ${ }^{1, b^{*}}$
}

\author{
${ }^{1}$ Department of Polymer Engineering, Faculty of Mechanical Engineering, Budapest University of \\ Technology and Economics, H-1111 Budapest, Múegyetem rkp. 3, Hungary
}

ae-mail: dobrovszky.karoly@mail.bme.hu, be-mail: ronkay@pt.bme.hu (corresponding author)

Keywords: polymer blend; phase inversion; tensile test; shrinkage; burning properties

\begin{abstract}
Blending polymers is an effective method to develop novel materials, tailoring the properties of the components. However, different morphology structures can be formed during the preparation, which could result in a wide diversity of mechanical and physical properties. The properties of polymer blends are most significantly influenced by the emerging range of phase inversion, which depends on the composition ratio and the viscosity ratio. In this paper various blends were prepared, utilizing polyethylene terephthalate (PET), polystyrene (PS) and two high density polyethylenes (HDPE), which differ in flowability. After preliminary homogenization by twin screw extruder, standard injection moulded specimen were prepared in order to present the effects of phase inversion on tensile properties, shrinkage and burning characteristics in binary polymer blends.
\end{abstract}

\section{Introduction}

Blending polymers is widely used in order to create new polymers for the ever-increasing demands, with which better properties can be achieved not only in mechanical properties, but also on the other physical properties of plastic materials. The forming morphology in binary polymer blends depends on the component's concentration and their viscosity ratio. The morphology can be classified by the concentration of the components: if either one is low a dispersed system forms, while around the symmetrical composition ratio a co-continuous structure can be detected. The maximum cocontinuity occurs at phase inversion, where the dispersed and matrix phases have vanished and the phases show only a continuous, meshed structure [1]. However, in case of blends where the viscosity of either component differs significantly from the other at same shear rate, the range of the cocontinuous structure can be shifted towards the plastic with higher viscosity [2]. Mortazavi et al. [3] reported the influence of phase inversion in polyethylene (PE) blend, where the tensile strength and Young's modulus rapidly changed. They also found that the mixing rule could predict the Young's modulus of blends with dispersed phase but not in the range of co-continuous morphology. Willemse et al. [4] reported, that morphology changing in polymer blends from droplet/matrix to co-continuous structure can result in a significant increase in modulus.

The most frequently used plastics, like polypropylene (PP), high density polyethylene (HDPE), polystyrene (PS) and polyethylene terephthalate (PET) can be found in large quantities in all the fields of industry. Numerous food packaging, automotive parts, electronic products and construction elements are made from these materials and their blends because of their low density and great damping properties. In the latter case, the application of plastics and polymer blends could also depend on greater resistance to burning [5] and dimensional stability, which is strongly influenced by the thermal shrinkage of the materials [6,7]. During the injection moulding process the shrinkage cannot be ignored because of the density difference between the melted state and the solidified plastic 
product. Fujiyama and Kimura [8] mentioned earlier that the shrinkage in flow direction is increasing with the thickness of the shell of injection moulded products. They also found a correlation between the thickness of the forming shell structure and the flowability. Wu et al. [7] mentioned that it is necessary to improve the low melting point and decrease the thermal shrinkage of HDPE separator in lithium-ion battery safety, driven by blending or using fillers to avoid the further thickness increasing of the wall. Kang [9] reported that the injection time is the most significant parameter on the volumetric shrinkage of injection moulded products. Chang et al. [10] submitted a patent according to computer-implemented method for calculating the shrinkage of moulding polymer products using viscosity and pressure-volume-temperature (pVT) properties. Rahimi et al. [6] investigated the reprocessing effect on shrinkage and tensile properties of plastics. It was found that reprocessing leads to smaller molecular chains and smaller shrinkage likewise.

Investigating the influence of developing morphology after injection moulding on other physical properties, like burning behaviour can also promote the usage of polymers in electronic and automotive fields. Sonnier et al. [11] found a relation between burning properties and morphology of thermoplastic blends, where the peak of heat release rate suddenly decreased, and at the same time the blends turned into self-extinguishing, when the relatively flammable polymer took place as a matrix in the blend. Walters and Lyon [12] found a relationship between the molar group contribution, the heat-release capacity and ignitability of plastics in PET/HDPE blends, where HDPE shows higher flammability. The heat-release capacity of HDPE $(1676 \mathrm{~J} / \mathrm{gK})$ was five times higher, until the total heat release $(41.6 \mathrm{~kJ} / \mathrm{g})$ was almost three times higher than PET.

In this present paper it was attempted to reveal a connection between the forming morphology, the tensile- and burning properties of different PET/HDPE and PS/HDPE blends. Another aim was to present the influence of phase inversion on mould-shrinkage characteristics of binary blends.

\section{Experimental}

Materials. PET/HDPE and PS/HDPE blends were prepared with the PET or PS-content ranging from $0 \mathrm{vol} \%$ to $100 \mathrm{vol} \%$, by increments of $10 \mathrm{vol} \%$. PET and PS were blended with two HDPE differing in flowability in a melted state because of difference in molecular weight. The measured melt flow index (MFI), the density values at room temperature and the tensile strength (given by the suppliers) of plastics are summarized in Table 1, with the utilized abbreviations later.

Table 1. Plastic types, producers and properties

\begin{tabular}{|c|c|c|c|c|c|c|}
\hline \multirow[t]{2}{*}{ Abbreviation } & \multirow[t]{2}{*}{ Trade name } & \multirow[t]{2}{*}{ Supplier name } & \multicolumn{2}{|c|}{$\begin{array}{c}\text { MFI with } \\
2.16 \mathrm{~kg} \text { weight load } \\
{[\mathrm{g} / 10 \mathrm{~min}]}\end{array}$} & \multirow[t]{2}{*}{$\begin{array}{l}\text { Density } \\
\text { at } 25^{\circ} \mathrm{C} \\
{\left[\mathrm{g} / \mathrm{cm}^{3}\right]}\end{array}$} & \multirow{2}{*}{$\begin{array}{c}\text { Tensile } \\
\text { strength by } \\
\text { producer } \\
\text { [MPa] }\end{array}$} \\
\hline & & & $255^{\circ} \mathrm{C}$ & $275^{\circ} \mathrm{C}$ & & \\
\hline HDPE-MOL & $\begin{array}{l}\text { Tipelin } \\
\text { BA 550-13 }\end{array}$ & $\begin{array}{l}\text { MOL } \\
\text { Petrochemicals } \\
\text { (Hungary) }\end{array}$ & $\begin{array}{c}0.30 \pm \\
0.2\end{array}$ & $\begin{array}{c}0.77 \pm \\
0.3\end{array}$ & 0.955 & 29 \\
\hline HDPE-UNI & Liten MB 87 & $\begin{array}{l}\text { Unipetrol RPA } \\
\text { (Czech Republic) }\end{array}$ & $\begin{array}{c}56.6 \pm \\
4.6\end{array}$ & $\begin{array}{c}73.7 \pm \\
6.2\end{array}$ & 0.955 & 22 \\
\hline PS & Edistir N1840 & Versalis (Italy) & $\begin{array}{c}17.9 \pm \\
0.7\end{array}$ & & 1.050 & 39 \\
\hline PET & NeoPET 80 & $\begin{array}{l}\text { Neogroup } \\
\text { (Lithuania) }\end{array}$ & & $\begin{array}{c}38.4 \pm \\
5.7\end{array}$ & 1.340 & $\begin{array}{c}56^{*} \\
\text { (measured) }\end{array}$ \\
\hline
\end{tabular}

Equipment. PET was dried in an air drying oven at $160^{\circ} \mathrm{C}$ for 6 hours. The extrusion took place in a Labtech Scientific LTE 26-44 twin screw extruder (in PET/HDPE blends temperature profile was 250 to $275^{\circ} \mathrm{C}$ with a rotation speed of $40 \mathrm{rpm}$; in PS/HDPE blends the temperature was 230 to $255^{\circ} \mathrm{C}$, the rotation speed was $75 \mathrm{rpm}$ ). The extrudates were cooled down in a water bath, followed by granulation. An Arburg Allrounder Advance 370S 700-290 was used to prepare the specimen with a $10 \times 4 \mathrm{~mm}$ cross section, according to ISO 527-2:2012 standard, where nozzle temperature was $275^{\circ} \mathrm{C}$ 
in case of PET blends and $255^{\circ} \mathrm{C}$ in case of PS blends. The applied injection flow was $30-40 \mathrm{~cm}^{3} / \mathrm{s}$, the holding pressure was $400 \pm 100$ bar at blends consisting of HDPE-UNI polyethylene, while $750 \pm 100$ bar was used in case of HDPE-MOL. The holding pressure was $70 \%$ of the injection pressure. Cooling time was $40 \mathrm{~s}$ in case of PET blends and $35 \mathrm{~s}$ in case of PS blend.

After gold coating, JEOL JSM 6380LA scanning electron microscope (SEM) was used in secondary electron imaging mode at an acceleration voltage of $15 \mathrm{kV}$, in order to trace the phase inversion range in PET/HDPE and PS/HDPE blends. The longitudinal shrinkage of the injection moulded specimen with $172 \mathrm{~mm}$ length was recorded 168 hours after the production, where the averages were determined by six samples for each composition. Tensile tests were performed on a Zwick Z020 Tester (test speed $20 \mathrm{~mm} / \mathrm{min}$, clamping distance $100 \mathrm{~mm}$ ) at room temperature, where 5 repetitions were done for each composition. According to ISO 4589 standard, limiting oxygen index (LOI) was measured on $10 \times 4 \times 80 \mathrm{~mm}$ specimens with \pm 0.5 accuracy.

\section{Results and discussion}

Morphology. Fig. 1 presents the developed co-continuous morphology of the core of blends with different flowability. Comparing the different types of polyethylenes, the blends consisting of HDPEMOL showed finer morphology than HDPE-UNI blends. Because of the lower flowability of HDPEMOL polyethylene the phase inversion took place at lower PET or PS content in HDPE-MOL based blends (Fig. 1(a) and Fig. 1(c)). In case of PET/HDPE-MOL blends the co-continuous morphology was detected between 30-50 vol\% of PET and over 60 vol\% PET content the fibrous structure of HDPE started to break up into elongated droplets. In case of PS/HDPE-MOL blends the phase inversion occurred between 40-60 vol\% PS content, respectively. Because of the high viscosity difference between the components, phase inversion was immediately realized when the PET and PS, characterized by higher flowability (Table 1), reached the required proportion forming a continuous structure. In contrast, utilizing HDPE-UNI polyethylene during the blend preparation, the range of phase inversion has shifted to higher PET or PS content because HDPE-UNI polyethylene can be characterized by higher flowability than PET and PS. The phase inversion occurred within a narrower range: 55-60 vol\% PET content in PET/HDPE-UNI blends (Fig. 1(b)), while in PS/HDPE-UNI blends between 60-70 vol\% PS content (in Fig. 1(d)) a coarsened co-continuous structure can be detected at 70 vol\% of PS content).

Mould-shrinkage. The longitudinal shrinkage of the injection moulded binary blends is presented in Fig. 2. Comparing the two different polyethylene based blends it can be stated, that PET/HDPE blends showed higher shrinkage than PS/HDPE blends. It can be also visible, that HDPE-MOL had greater shrinkage as a function of time than HDPE-UNI. The shrinkage 168 hours after the production of the neat HDPE-MOL, HDPE-UNI, PET and PS were 3.3\%, $2.4 \%, 0.8 \%$ and $0.5 \%$, respectively. The measured shrinkage values differ from the theoretical values, calculated from the linear mixing rule in every blend, which means that the shrinkage depends not only on composition, but also on the forming morphology structure. Investigating the HDPE-MOL based blends (Fig. 2(a)) it was found, that the co-continuous morphology was developed from 30 to 50 vol\% of PET and in a range of 40-60 vol\% PS content, respectively. After $50 \mathrm{vol} \%$ of PET content a larger decrease can be observed in the trend because the HDPE-MOL lost its continuity in PET/HDPEMOL blends, and only PET formed the matrix, in which HDPE-MOL showed an elongated dispersed shape, as we had described in our previous study [2]. From 60 vol\% of PET content the shrinkage of the PET/HDPE-MOL blends are well comparable with the shrinkage of the neat PET. A similar breakpoint can be detected in case of PS/HDPE-MOL blends. As long as the HDPE formed a continuous structure (until 60 vol\% of PS) the shrinkage continuously decreased parallel increasing the PS content in blends. Above $60 \mathrm{vol} \%$ of PS, when the phase inversion took place, only a slight difference can be detected comparing the shrinkage of PS/HDPE-MOL blends and PS.

However, HDPE-UNI had smaller shrinkage than HDPE-MOL, the same phenomenon can be observed at PET/HDPE-UNI and PS/HDPE-UNI blends (Fig. 2(b)). When HDPE-UNI showed continuous morphology (up to 60 vol\% of PET and 70 vol\% of PS) the shrinkage of the blends was 
steadily decreased as the PET or PS content increased. After the phase inversion a breakpoint can be detected in the curves, and in case when PET and PS formed the matrix, the shrinkage of the blends and the neat plastics was approximately the same. This phenomenon can be explained by the fact, that both HDPEs have greater shrinkage than PET and PS, therefore increasing the proportion of PET and PS in blends increasingly inhibited the shrinkage until the end of the phase inversion, when both HDPEs lost their continuity. As a result, neither HDPE has influence on the shrinkage of blends, when PET and PS form the matrix.

Tensile tests. Fig. 3(a) presents the tensile strength and Young's modulus of HDPE-MOL based polymer blends, while Fig. 3(b) shows the same mechanical properties of HDPE-UNI based blends. Generally it can be stated, that the values of Young's modulus of each polymer blend follows rather a straight line based on the mixing rule, regardless of the composition ratio. On the other hand the forming morphology has great influence on the tensile strength values, particularly in the HDPE-UNI based blends because of the coarsened morphology. As long as the HDPE-UNI formed the matrix structure, the tensile strength values $(20.4 \mathrm{MPa})$ of the blends were the same or lower as the neat HDPE-UNI. The tensile strength of PET/HDPE-UNI has increased by $70 \%$ in the range of phase inversion (50-55 vol\% PET content). In PS/HDPE-UNI blends the tensile strength also increased by $20 \%$ (from 21.0 MPa to $25.3 \mathrm{MPa}$ ) in the range of phase inversion at $60-70 \mathrm{vol} \%$ of PS content. In contrast, the tensile strength was the same or lower as HDPE-UNI from 0 to 60 vol\% of PS content. Because different injection temperatures were utilized in PET $\left(275^{\circ} \mathrm{C}\right)$ and PS $\left(255^{\circ} \mathrm{C}\right)$ based blends, a slight difference can be detected in the tensile values at the neat HDPEs, and it should be declared that the standard deviations are shown in each case in Fig. 3.

Burning properties. The results of the limiting oxygen index (LOI) measurements are presented in Fig. 4. Comparing the applied plastics, it can be stated that PET shows the highest resistance against burning. The presence of $26 \%$ of oxygen was necessary for continuous combustion in oxygen/nitrogen atmosphere in case of PET. $18.5 \%$ of oxygen was needed to achieve the stable combustion in case of the two different flowability HDPE, while the least amount of oxygen was required in case of PS (LOI=17.5). Tracing the effect of the phase inversion is quite easy in both HDPE-MOL and HDPE-UNI based blends, after investigating the values of LOI. As long as the HDPE formed the matrix in binary blends the LOI values are located in the range of HDPE $(\mathrm{LOI}=18.5 \pm 0.5)$. Subsequently, the LOI values started to alter in the range of the phase inversion and the LOI values began to rise when PET has started to form the matrix structure (above 60 vol\% of PET), while the LOI values of blends containing PS was slightly decreased when PS formed continuous structure in the blends.

\section{Conclusion}

In this study the effect of phase inversion on mould-shrinkage, tensile- and burning properties was investigated in PET/HDPE and PS/HDPE polymer blends. The longitudinal shrinkage of injection moulded blends was traceable in the whole range of content. A strong correlation was detected between shrinkage and forming morphology. Increasing the amount of PS and PET gradually inhibits the shrinkage of HDPE matrix based blends because of the different shrinkage of plastics. After the phase inversion, HDPE had no influence on the shrinkage of PS or PET matrix based blends due to the higher geometrical change. Similarly, between the range of phase inversion and the changing of limiting oxygen index (LOI) another correlation was found. By investigating the results of tensile test it can be said, that the forming morphology had influence on tensile strength, while the Young's modulus only depended on the compositional ratio.

Acknowledgement. This research was realized in the frameworks of TÁMOP 4.2.4. A/1-11-1-20120001 "National Excellence Program - Elaborating and operating an inland student and researcher personal support system". The project was subsidized by the European Union and co-financed by the European Social Fund. The infrastructure of the research project was supported by the Hungarian Scientific Research Fund (OTKA K109224). 


\section{References}

[1] L.A. Utracki, C.A. Wilkie, Polymer Blends Handbook, second ed., Springer, Dordrecht, 2014.

[2] K. Dobrovszky, F. Ronkay, Effects of SEBS-g-MA on rheology, morphology and mechanical properties of PET/HDPE blends, Int. Polym. Proc. 30 (2015) 91-99.

[3] S. Mortazavi, I. Ghasemi, A. Oromiehie, Effect of phase inversion on the physical and mechanical properties of low density polyethylene/thermoplastic starch, Polym. Test. 32 (2013) 482491.

[4] R.C. Willemse, A. Speijer, A.E. Langeraar, A. Posthuma de Boer, Tensile moduli of cocontinuous polymer blends, Polymer 40 (1999) 6645-6650.

[5] B. Bodzay, M. Fejős, K. Bocz, A. Toldy, F. Ronkay, Gy. Marosi, Upgrading of recycled polypropylene by preparing flame retarded layered composite, Express Polym. Lett. 6 (2012) 895902.

[6] M. Rahimi, M. Esfahanian, M. Moradi, Effect of reprocessing on shrinkage and mechanical properties of ABS and investigating the proper blend of virgin and recycled ABS in injection molding, J. Mater. Process. Tech. 214 (2014) 2359-2365.

[7] Y-C. Wu, Y-H. Cui, H-L. Jin, C-C. Ning, Study on the preparation and thermal shrinkage properties of nano-SiO2/UHMWPE/HDPE blend microporous membranes, J. Appl. Polym. Sci. 132 (2015) 41321/1-8.

[8] M. Fujiyama, S. Kimura, Effect of molecular parameters on the shrinkage of injection-molded polypropylene, J. Appl. Polym. Sci. 22 (1978) 1225-1241.

[9] G-J. Kang, Process Factor Optimization for reducing warpage and shrinkage in injection molding using design of experiments, Appl. Mech. Mater. 541-542 (2014) 359-362.

[10] R.Y. Chang, C.H. Hsu, H.S. Chiu, S.P. Sun, C.C. Wang, H.C. Tseng, Predicting shrinkage of injection molded products with viscoelastic characteristic, U.S. Patent: 8768662 B2 (2014).

[11] R. Sonnier, A. Viretto, A. Taguet and J-M. Lopez-Cuesta, Influence of the morphology on the fire behavior of a polycarbonate/poly(butylene terephthalate) blend, J. Appl. Polym. Sci. 125 (2012) 3148-3158.

[12] R.N. Walters, R.E. Lyon, Molar group contributions to polymer flammability, J. Appl. Polym. Sci. 87 (2003) 548-563. 

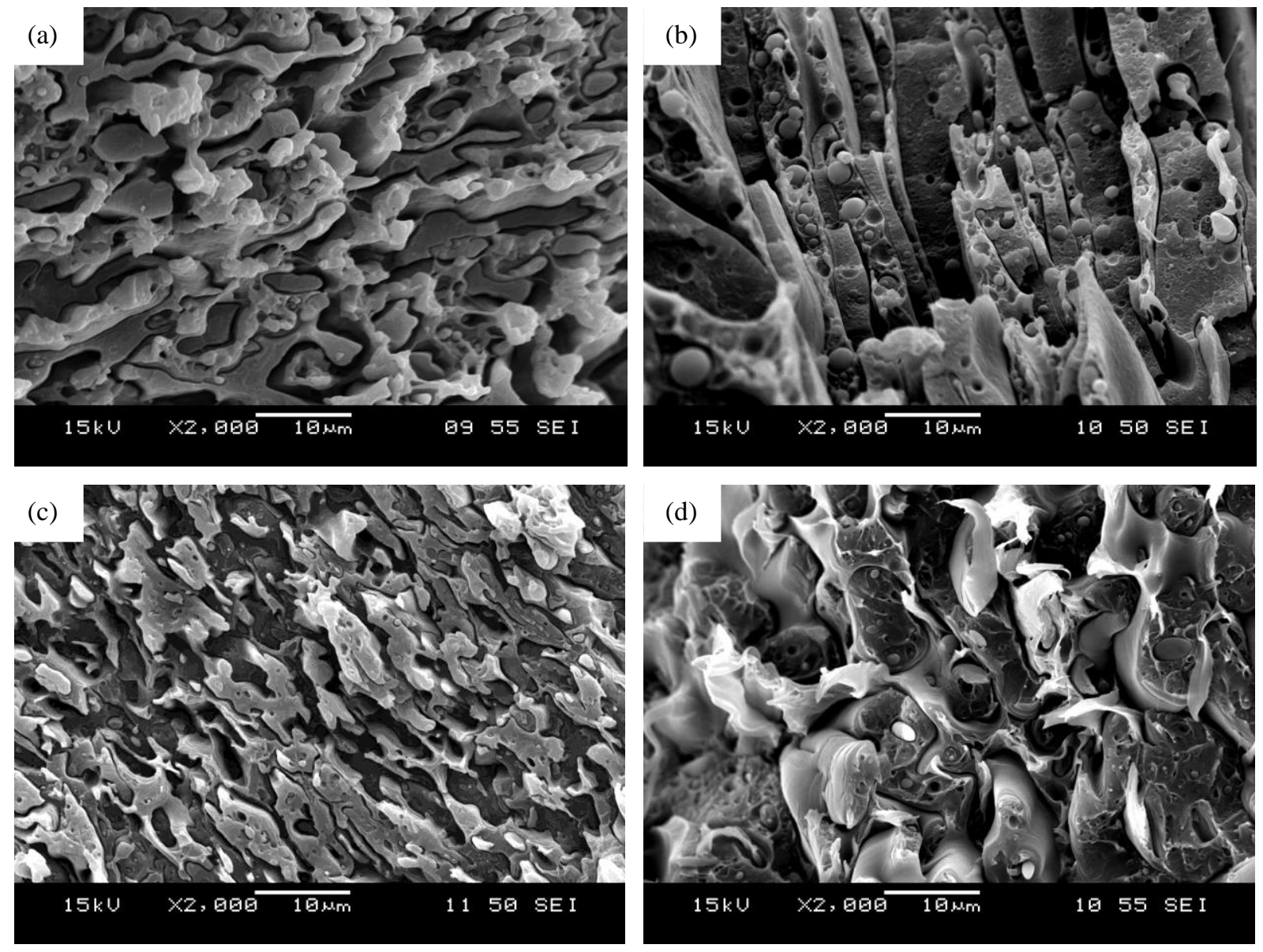

Figure 1. Fully co-continuous morphology at composition ratio in binary blends: a) 30/70 vol\% PET/HDPE-MOL; b) 55/45 vol\% PET/HDPE-UNI; c) 40/60 vol\% PS/HDPE-MOL; d) 70/30 vol\% PS/HDPE-UNI 


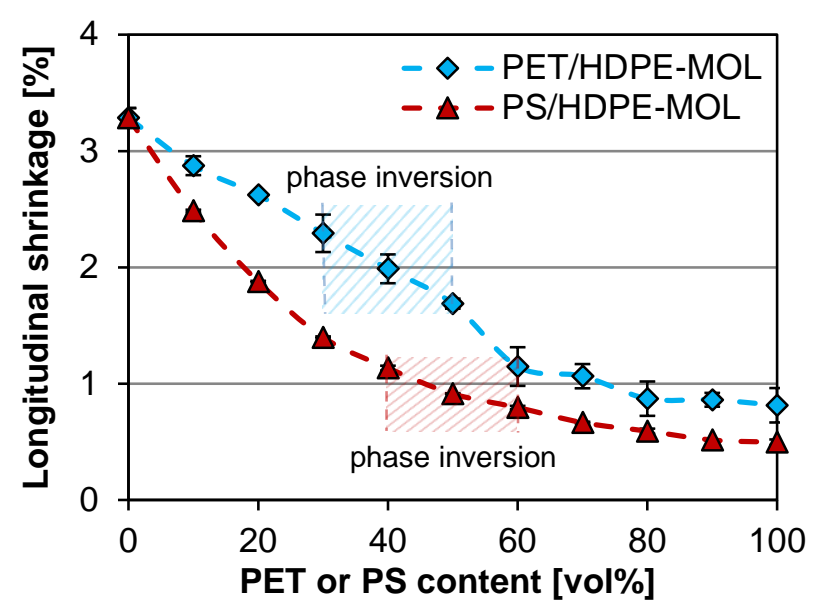

(a)

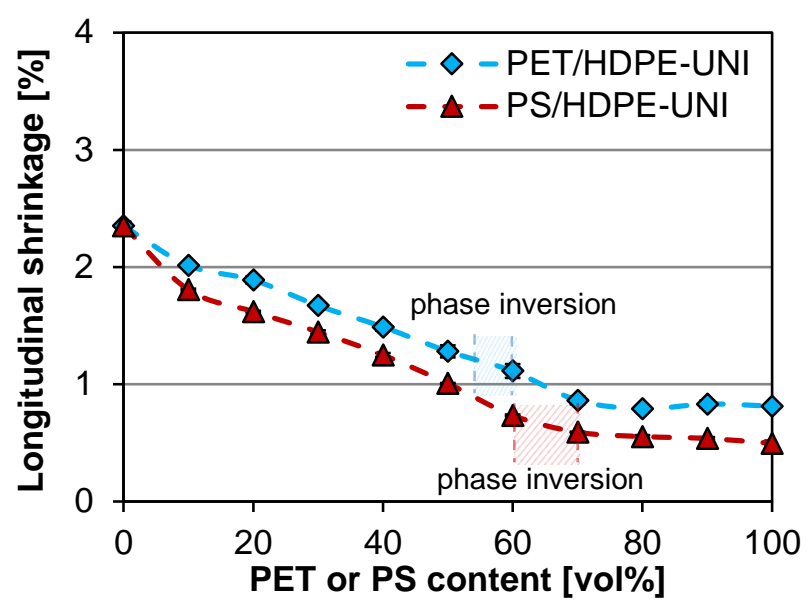

(b)

Figure 2. Longitudinal shrinkage of the injection moulded PET/HDPE and PS/HDPE blends 168 hours after the production: (a) HDPE-MOL based; (b) HDPE-UNI based blends 


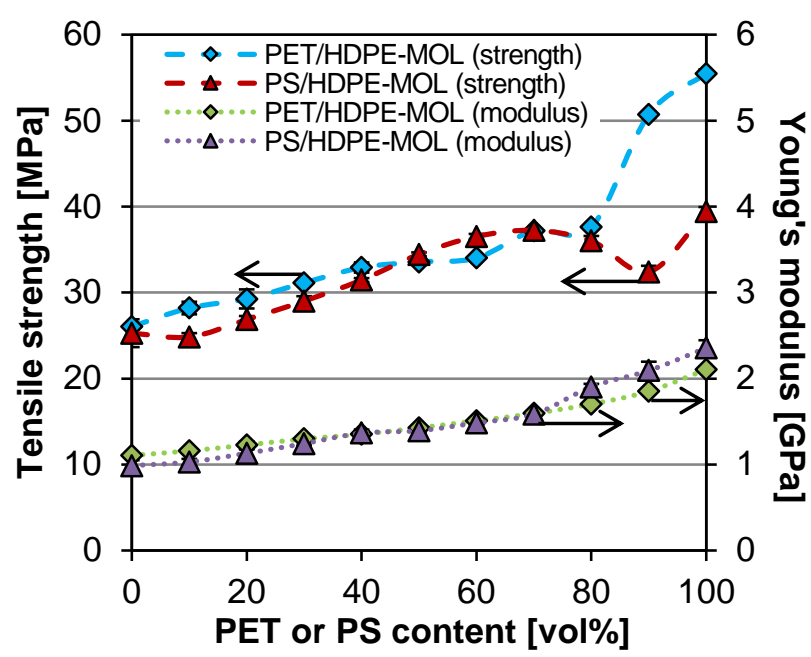

(a)

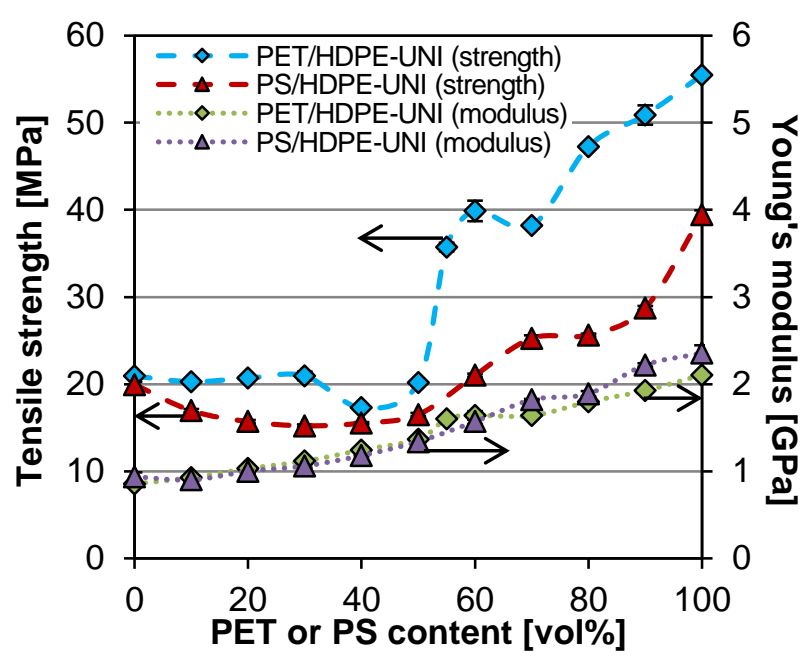

(b)

Figure 3. Tensile strength and Young's modulus at different PET or PS content in PET/HDPE and PS/HDPE blends: (a) HDPE-MOL based; (b) HDPE-UNI based blends 


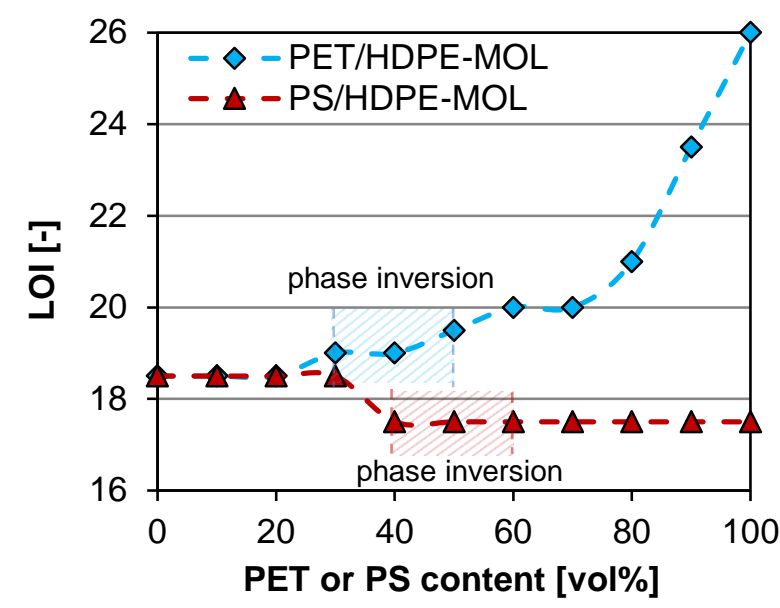

(a)

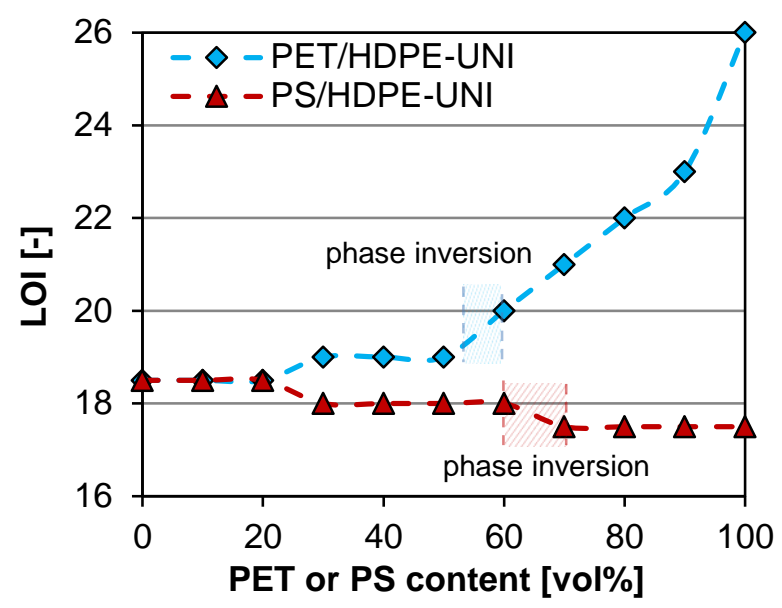

(b)

Figure 4. LOI values of PET/HDPE and PS/HDPE blends at different PET or PS content: (a) HDPE-MOL based; (b) HDPE-UNI based blends 